\title{
Management of dysfunctional uterine bleeding based on endometrial thickness
}

This article was published in the following Dove Press journal:

International Journal of Women's Health

3I August 2010

Number of times this article has been viewed

\author{
Ozgul Muneyyirci-Delale ${ }^{1,2}$ \\ Anuja Gupta ${ }^{1,2}$ \\ Cynthia Abraham' \\ Ashadeep Chandrareddy' \\ Charles $\mathrm{H}$ Bowers $\mathrm{Jr}^{2}$ \\ Jed B Cutler ${ }^{2}$
}

Departments of Obstetrics and Gynecology, 'SUNY Downstate Medical Center, ${ }^{2}$ Kings County Hospital Center, Brooklyn, New York, USA

Correspondence: Ozgul Muneyyirci-Delale Division of Reproductive Endocrinology and Infertility, Department of Obstetrics and Gynecology, SUNY Downstate Medical Center. 450 Clarkson Avenue, Box \# 24, Brooklyn, New York I I 203, USA $\mathrm{Tel}+\mathrm{I} 7182702101$

Fax +I 7182702067

Email ozgul.muneyyirci-delale@ downstate.edu
Objective: To manage patients with dysfunctional uterine bleeding (DUB) according to endometrial thickness.

Methods: A retrospective chart review of 49 patients who reported 8 or more days of bleeding was performed. They were then divided into three groups based on endometrial thickness $(\mathrm{mm})$ : less than 6,6-11, and greater than 11 . These three groups were treated with combined oral contraceptive pills (OCP), conjugated estrogen plus progesterone and megestrol respectively. Patients given megestrol also underwent endometrial biopsy before treatment. Patients recorded the degree of bleeding each day for one month after starting treatment.

Results: Mean endometrial thickness in the combined OCPs, conjugated estrogen plus progesterone and megestrol groups were 4,8 and $14 \mathrm{~mm}$, respectively. Combined OCPs decreased bleeding from 46 to 8 days $(P<0.05, \mathrm{n}=8)$. Conjugated estrogen plus progesterone decreased the number of days of bleeding from a mean of 41 to $9(P<0.01, \mathrm{n}=16)$. Megestrol decreased bleeding from 54 to 3 days $(P<0.001, \mathrm{n}=25) .52 \%$ of patients given megestrol had endometrial hyperplasia.

Conclusion: These results support the effectiveness of treating patients with DUB according to endometrial thickness.

Keywords: DUB, abnormal uterine bleeding, endometrium, hyperplasia, megestrol acetate

\section{Introduction}

Dysfunctional uterine bleeding (DUB) is a common debilitating problem amongst women in all age groups and accounts for $20 \%$ of gynecology office visits. ${ }^{1}$ It is defined as abnormal, irregular bleeding (excessively heavy, prolonged, or frequent intervals of bleeding) in the absence of demonstrable pelvic disease, complications of pregnancy or systemic disease. ${ }^{2-5}$ The exact mechanism is uncertain but is thought to be caused by dysfunction of hypothalamic-pituitary-ovarian axis. ${ }^{6}$

Diagnosis can be made by excluding intrauterine pathology like submucosal myomas and polyps using transvaginal sonogram (TVS) or saline infusion sonogram (SIS). TVS has lower sensitivity and specificity in detecting intrauterine abnormalities compared to SIS. However an approach using endometrial thickness measurement by TVS to further determine the diagnostic and treatment options is an effective and non invasive way to triage premenopausal patients with DUB. ${ }^{7}$ In postmenopausal women with abnormal bleeding, the role of endometrial thickness measurement is well established and a $4-5 \mathrm{~mm}$ cut off value has a high negative predictive value in excluding endometrial hyperplasia or cancer. ${ }^{8}$ The current medical options for initial 
management of DUB are based on clinical presentation and severity and include high dose estrogens, combined estrogen and progesterone or progesterone alone. However there is insufficient data regarding their dose, duration and effectiveness and the treatment usually requires a trial of one of more available options.

The objective of our study is to investigate the utility of treating dysfunctional uterine bleeding based on endometrial thickness instead of solely on clinical presentation. The goal is to determine if tailoring hormone therapy to endometrial thickness as detected by TVS improves the management of this condition.

\section{Material and method}

This study is a retrospective chart review of patients with dysfunctional uterine bleeding (DUB) who received medical treatment in our reproductive endocrinology service. The study was approved by Institutional Review Board of SUNY Downstate Medical center and Kings County Hospital Center.

DUB was diagnosed in presence of excessive, prolonged, or frequent intervals of bleeding for eight or more days, unrelated to anatomic lesions or systemic disease. A complete history and physical examination was performed and routine laboratory tests were obtained to exclude systemic causes of bleeding. All patients underwent TVS to exclude uterine pathology and to assess the endometrial thickness (ET).

Patients without underlying anatomic or systemic pathology were offered hormonal treatment based on endometrial thickness. The management scheme is outlined in Figure 1. Patients with endometrial thickness of less than $6 \mathrm{~mm}$ were treated with combination of Ethinyl estradiol $0.035 \mathrm{mg}$ and norgestimate $0.25 \mathrm{mg}$, one pill daily for 28 days. Patients with endometrial thickness of 6-11 mm were treated with conjugated estrogen $2.5 \mathrm{mg}$ PO twice daily for one week then $2.5 \mathrm{mg}$ PO once daily for next week followed by $1.25 \mathrm{mg}$ PO once daily for further two weeks. Medroxyprogesterone pill $10 \mathrm{mg}$ was also given for the last two weeks. Patients with endometrial thickness of $12 \mathrm{~mm}$ or greater underwent endometrial biopsy to exclude malignancy and were treated with megestrol acetate $40 \mathrm{mg}$ daily. In event of endometrial carcinoma, patients were referred to gynecology-oncology service. All the three groups of patients also received azithromycin to prevent and treat endometritis secondary to prolonged bleeding.

Patients were given menstrual calendars to grade bleeding each day for one month beginning at the onset of treatment. Grading system was as follows: 0 - no bleeding, 1 - scanty bleeding, 2 - moderate bleeding, 3 - heavy bleeding, and 4 - heavy bleeding with clots. A bleeding score was calculated by adding all grades on calendar for the entire month. Fifty premenopausal patients with DUB who were treated as described above were included. Patients with bleeding disorders or with intrauterine pathology like fibroids, polyps, or endometrial cancer were excluded from the study.

Eligible patients were divided into three groups based on endometrial thickness and treatment offered. Group I (ET $<6 \mathrm{~mm}$ ), Group II (ET 6-11 mm), Group III $(\mathrm{ET}>12 \mathrm{~mm})$. For all patients information regarding age, BMI, age at menarche, cycle regularity and frequency, endometrial thickness, number of days of bleeding prior to treatment, number of days of bleeding after onset of treatment, and bleeding score were recorded. For patients in Group III results of endometrial biopsy were also recorded.

Comparison of the patient characteristics for all three groups was made using repeated measures ANOVA (SPSS, version 16) with $P$ value of 0.05 and confidence interval set at $95 \%$. The difference between mean number of days of bleeding prior to treatment and at the onset of treatment was also compared for all three groups using ANOVA pair wise comparisons. Student $t$-test was used to compare patient characteristics for patients with and without endometrial hyperplasia within Group III.

\section{Results}

Retrospective chart review of 50 patients was performed. Menstrual diary for one patient was not available and was excluded from the study. Patient characteristics are summarized in Table 1 . Mean patient age was $28 \pm 1.0$ years and was similar in all three groups. Mean BMI was $34 \pm 1.3$ and approached significant positive correlation with endometrial thickness $(\mathrm{r}=0.281, P=0.056)$. BMI also positively correlated with number of days of bleeding prior to treatment $(\mathrm{r}=0.343, P<0.05)$. The mean number of days of bleeding prior to treatment was similar in all three groups. $75 \%$ of patients reported irregular menstrual cycles consistent with anovulatory bleeding. Mean endometrial thickness for combined OCP $(n=8)$, conjugated estrogen + progesterone $(n=16)$ and megestrol acetate $(\mathrm{n}=25)$ groups were $4.2 \pm 0.3,8.0 \pm 0.5$, and $14.1 \pm 2.6 \mathrm{~mm}$ respectively.

All three treatments significantly decreased the number of days of bleeding after onset of treatment. Combined OCPs decreased the number of days of bleeding from 


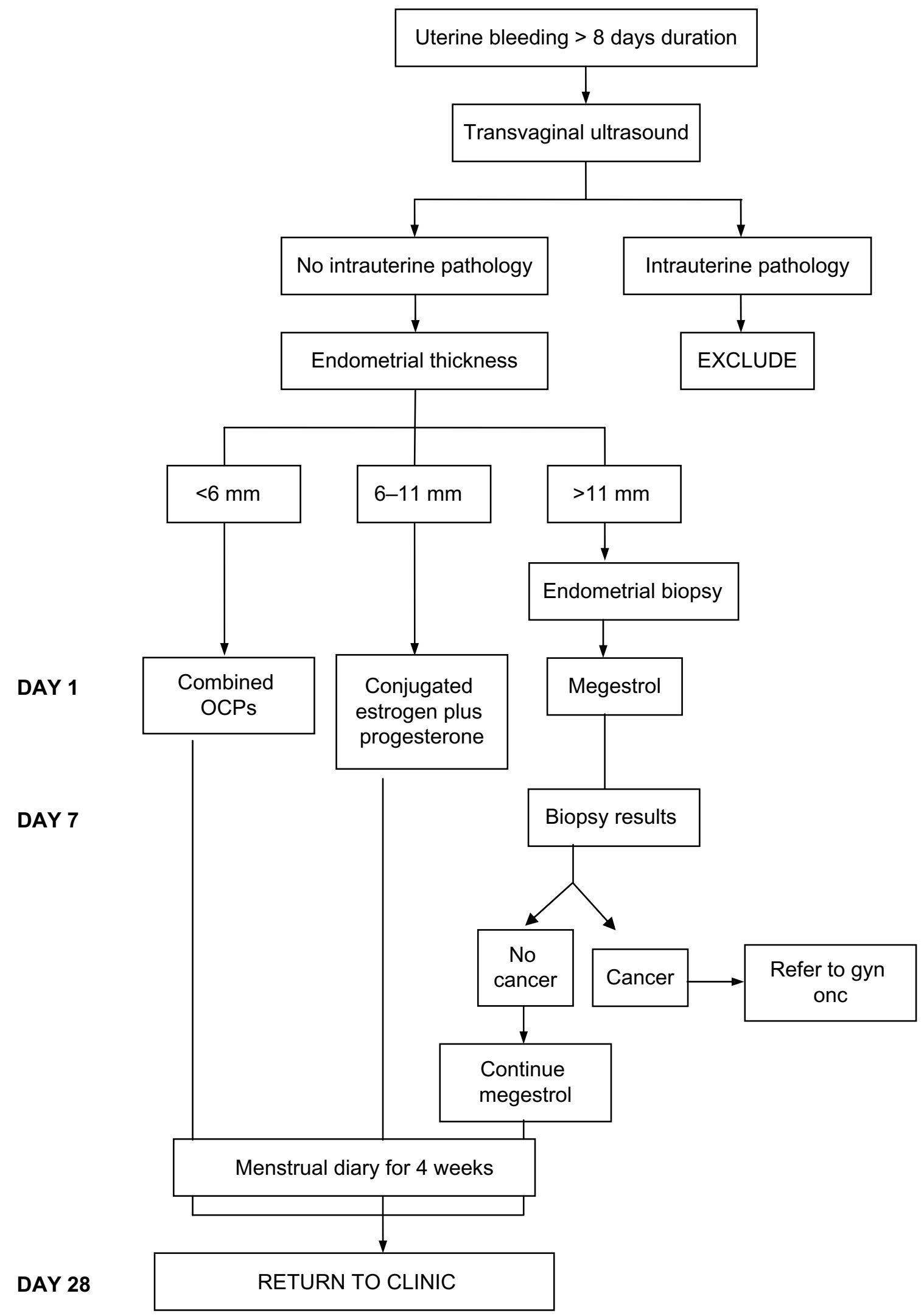

Figure I Management scheme used for dysfunctional uterine bleeding. 
Table I Patient demographic and clinical characteristics

\begin{tabular}{llll}
\hline $\begin{array}{l}\text { Treatment } \\
\text { groups }\end{array}$ & $\begin{array}{l}\text { Combined } \\
\text { OCPs } \\
(\mathbf{n}=\mathbf{8})\end{array}$ & $\begin{array}{l}\text { Conjugated } \\
\text { estrogen } \\
\text { progesterone } \\
(\mathbf{n}=16)\end{array}$ & $\begin{array}{l}\text { Megestrol } \\
(\mathbf{n}=\mathbf{2 5})\end{array}$ \\
\hline Age (years) & $23 \pm 2$ & $29 \pm 2$ & $29 \pm 1$ \\
BMI & $29 \pm 3$ & $32 \pm 2$ & $37 \pm 2$ \\
Menarche (years) & $12 \pm 0.5$ & $12 \pm 0.5$ & $12 \pm 0.3$ \\
$\begin{array}{l}\text { Cycle regularity (\%) } \\
\text { Number of }\end{array}$ & $25 \%$ & $25 \%$ & $20 \%$ \\
$\begin{array}{l}\text { cycles per year } \\
\text { Endometrial } \\
\text { thickness (mm) }\end{array}$ & $9 \pm 2$ & $7 \pm 1$ & $7 \pm 1$ \\
$\begin{array}{l}\text { Number of days of } \\
\text { bleeding prior } \\
\text { to treatment }\end{array}$ & $46 \pm 14$ & $41 \pm 8$ & $14.2 \pm 0.6$ \\
\hline
\end{tabular}

a mean of $46 \pm 14$ days to $8 \pm 3$ days $(P<0.05)$. Conjugated estrogen and progesterone decreased the number of days of bleeding from a mean of $41 \pm 8$ days to $9 \pm 2$ days $(P=0.001)$. Megestrol decreased bleeding from $54 \pm 8$ days to $3 \pm 7$ days $(P<0.001)$. Improvement in uterine bleeding with the three different treatments is plotted in Figure 2.

Bleeding score was found to be lowest in megestrol group (4.9 \pm 1.1$)$ compared to other two groups (Figure 3 ).

Patient characteristics of patients with and without endometrial hyperplasia were compared within megestrol group as shown in Table 2. Endometrial hyperplasia was seen in $52 \%$ of patients within group III. Those patients with endometrial hyperplasia had a significantly higher mean BMI $(40.8 \pm 3.1)$ than those without $(31.7 \pm 1.8, P<0.05)$. There was no significant difference in either the number of days bleeding prior to or after treatment between these two subgroups. There was also no significant difference in the bleeding score between them.

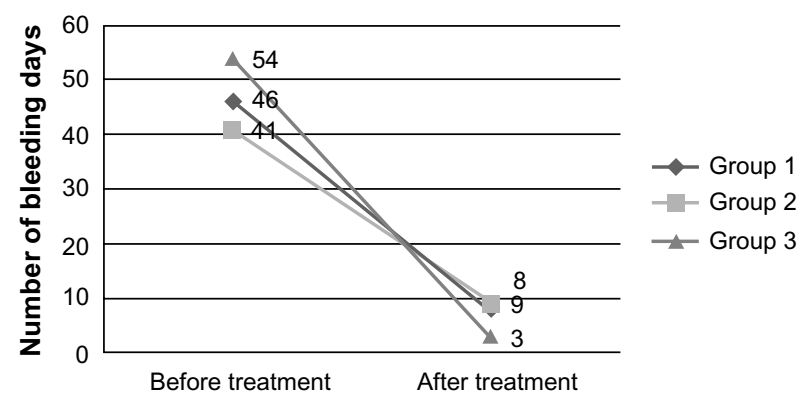

Figure 2 Number of bleeding before and after hormonal therapy.

\section{Discussion}

TVS is an excellent non-invasive tool to diagnose anatomic causes of dysfunctional uterine bleeding. ${ }^{9}$ A study by de Vries et al recommends evaluation of endometrial thickness by TVS as initial approach for premenopausal patient with DUB. ${ }^{7}$ For patients with ET of greater than $5 \mathrm{~mm}$, SIS is recommended to further determine the need for diagnostic hysteroscopy and to determine appropriate treatment options. Another study by Batzer supports TVS as an effective method to determine the need and type of surgical treatment for patients with DUB.$^{10}$ Traditionally however TVS has a limited role in medical treatment of DUB if any.

Our literature search in PUBMED and MEDLINE revealed no mention of prior studies investigating the utility of endometrial thickness as detected by TVS in medical treatment of DUB.

We obtained significant reduction in duration and severity of bleeding by tailoring hormonal treatment based on endometrial thickness cut off values. We used monophasic OCPs for ET less than $6 \mathrm{~mm}$ based on underlying etiopathogenesis. A thin endometrial stripe is a result of denuded endometrium secondary to prolonged bleeding. The estrogen component of OCP stimulates uniform endometrial growth and promptly stops shedding, while the progesterone component stabilizes the endometrium by converting it into pseudodecidua. ${ }^{11}$

With increasing ET between $6-11 \mathrm{~mm}$ we used oral conjugated estrogen followed by progesterone to stabilize the estrogen stimulated endometrial growth. The mechanism of action of conjugated estrogen is similar to intravenous estrogen and acts by stimulating clotting at the capillary level. ${ }^{12}$ Added advantage of using oral conjugated estrogen is the ability to treat patients in an outpatient setting.

For ET more than $11 \mathrm{~mm}$ we used megestrol acetate, which is a powerful antiestrogen known to prevent and reverse endometrial hyperplasia. ${ }^{13}$

Amongst the three treatment regimens, megestrol acetate was the fastest at suppressing uterine bleeding from a mean of 54 days to 3 days with the lowest bleeding score $(4.9 \pm 1.1)$. It was equally effective for treating both patients with and without endometrial hyperplasia who had ET of more than $11 \mathrm{~mm}$.

Use of megestrol for treatment of endometrial hyperplasia is well known however no previous studies have compared megestrol with other hormonal therapies for treatment of DUB.

A randomized clinical trial by Munro et al compared oral medroxyprogesterone with combined OCPs and found them equally effective in treating acute uterine bleeding. ${ }^{14}$ Their 


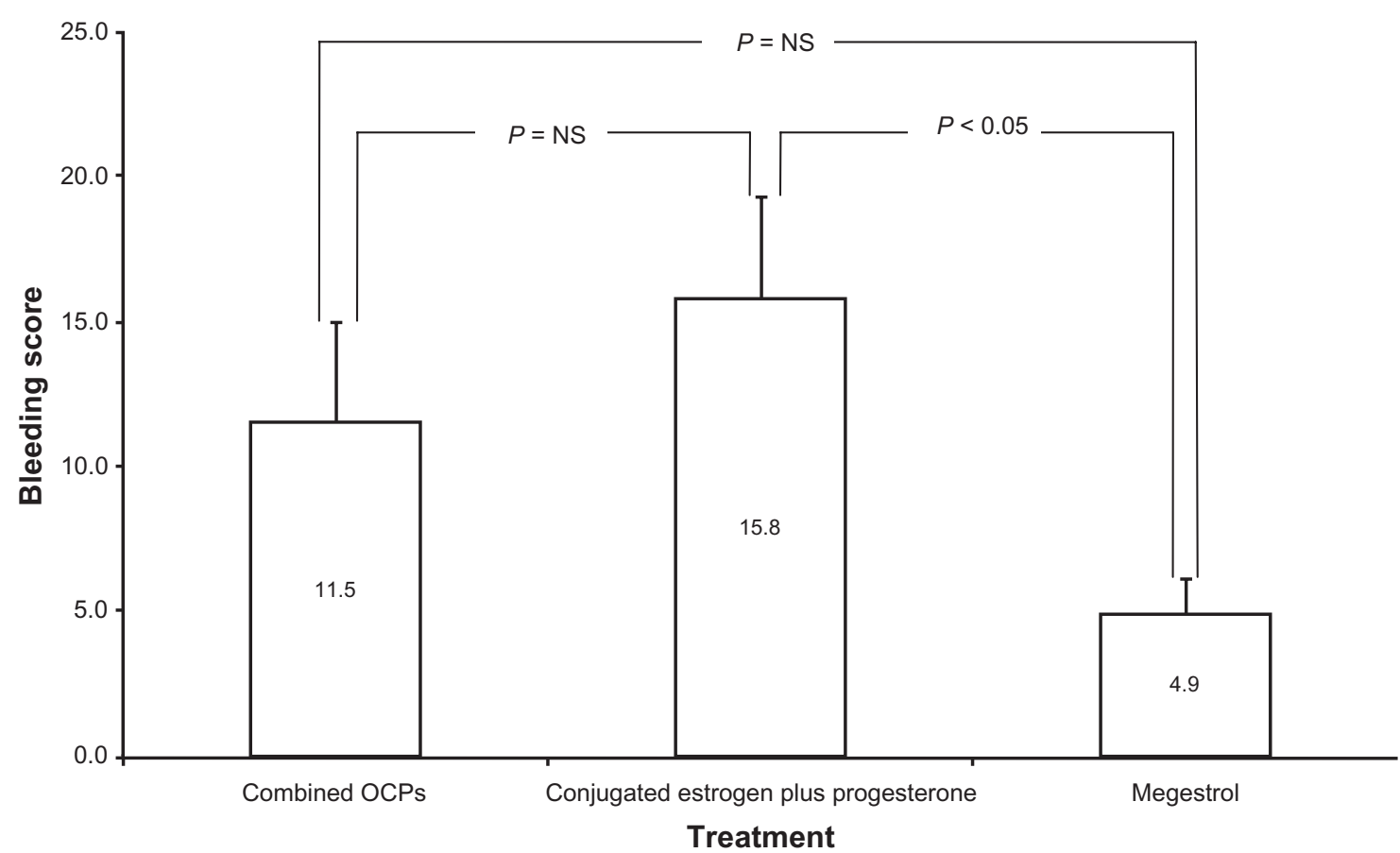

Figure 3 Bleeding scores after treatment.

study was limited by a small sample size and was unable to demonstrate statistically significant difference in between the treatment regimens. In contrast to our study, they utilized high dose regimen for initial one week followed by low dose for additional three weeks.

Another randomized controlled trial by Devore et a ${ }^{15}$ compared intravenous conjugated estrogens with placebo in patients with acute uterine bleeding and found significant reduction in bleeding with conjugated intravenous estrogens. We used oral conjugated estrogens for patients with endometrial thickness between $6 \mathrm{~mm}$ to $11 \mathrm{~mm}$, and in contrast to intravenous estrogen, patients can be treated on an outpatient basis.

Endometrial biopsy was performed in our study for ET greater than $11 \mathrm{~mm}$ and endometrial hyperplasia was detected in more than fifty percent of patients in this group. A study by Paraskevaidis et al showed an endometrial thickness cut off values of $13 \mathrm{~mm}$ has sensitivity, specificity, and positive predictive value of $100 \%, 71.6 \%$, and $40.6 \%$ respectively to detect endometrial abnormalities in perimenopausal women. ${ }^{16}$ Another recent study by Getpook et al showed that ET of $8 \mathrm{~mm}$ or less is unlikely to be associated with malignant pathology. ${ }^{17}$ Although we were able to establish the presence of endometrial hyperplasia in those with thick endometrium, we were not able to exclude it in those with thinner endometrium stripes (less than $11 \mathrm{~mm}$ ).
Incidence of endometrial hyperplasia in our study group was $26.5 \%(n=13)$. This was significantly higher than the incidence of endometrial hyperplasia in premenopausal women in general quoted as $2 \%-10 \% .^{18}$

Mean BMI in our study was 34 with significant positive correlation with endometrial thickness. Higher BMI was also noted in patients with endometrial hyperplasia. This finding supports obesity and increased BMI as a risk factor for anovulatory bleeding and endometrial hyperplasia. ${ }^{16}$ It can also be suggested that patients with higher BMI who suffer from anovulatory bleeding may need endometrial biopsy regardless of endometrial thickness.

The primary strength of our study was that patients within the three groups had similar demographic and

Table 2 Characteristics of patients treated with megestrol acetate

\begin{tabular}{lll}
\hline Group & $\begin{array}{l}\text { No endometrial } \\
\text { hyperplasia } \\
(\mathbf{n}=\mathbf{~ I 2})\end{array}$ & $\begin{array}{l}\text { Endometrial } \\
\text { hyperplasia } \\
(\mathbf{n}=\mathbf{~ I 3 )}\end{array}$ \\
\hline Age (years) & $29 \pm 3$ & $29 \pm 2$ \\
BMI & $31.8 \pm 1.8$ & $40.1 \pm 3.4$ \\
Endometrial thickness (mm) & $14.5 \pm 0.6$ & $13.8 \pm 0.9$ \\
$\begin{array}{l}\text { Number of bleeding days prior } \\
\text { to treatment }\end{array}$ & $42 \pm 5$ & $66 \pm 14$ \\
Number of bleeding days & $3 \pm 1$ & $3 \pm 1$ \\
after treatment & & $5.4 \pm 1.5$ \\
Bleeding score & $4.4 \pm 1.8$ & \\
\hline
\end{tabular}


clinical characteristics with only significant difference in their endometrial thickness. Although our sample size was small, we were able to get significant reduction in bleeding values in all three groups. The principal limitation was the lack of controls for each group. Randomized prospective trial will be needed to further substantiate our findings.

In summary we conclude that management of DUB based on endometrial thickness is an effective approach to control acute uterine bleeding. Our study emphasizes on the medical treatment of acute DUB only. Further evaluation is recommended to determine the need for management of patients with chronic DUB.

\section{Disclosure}

The authors report no conflicts of interest in this work.

\section{References}

1. Awwad JT, Toth TL, Schiff I. Abnormal uterine bleeding in the perimenopause. Int J Fertil. 1993;38:261.

2. Crosignani PG, Rubin B. Dysfunctional uterine bleeding. Hum Reprod. 1990;5:637-638.

3. Fraser IS. The dysfunctional uterus - dysmenorrhoea and dysfunctional uterine bleeding. In: Shearman RP, editor. Textbook of clinical reproductive endocrinology. Edinburgh: Churchill Livingstone. 1985; 578-598.

4. Fraser IS, Hickey M, Song JY. A comparison of mechanisms underlying disturbances of bleeding caused by spontaneous dysfunctional uterine bleeding or hormonal contraception. Hum Reprod. 1996;11 Suppl 2: 165-178.

5. Fraser IS, Sungurtekin U. Defining menstrual disturbances. In: Maclean A, O' Brien PMS (editors). Study Group on Menstrual Disorders. Royal College of Obstetricians and Gynaecologists. 2000. p. 141-152.

6. Livingstone M, Fraser IS. Mechanisms of abnormal uterine bleeding. Hum Reprod Update. 2002;8:60-67.
7. de Vries LD, Dijkhuizen FP, Mol BW, Brötmann HA, Moret E, Heintz AP. Comparison of transvaginal sonography, saline infusion sonography, and hysteroscopy in premenopausal women with abnormal uterine bleeding. J Clin Ultrasound. 2000;28(5):217-223.

8. Machado LS, Mathew M, Al-Hassani A, Vaclavinkova V. Correlation of endometrial thickness, cycle day and histopathology in women with abnormal uterine bleeding. Saudi Med J. 2005;26(2):260-263.

9. Mortakis A, Mavrelos K. Transvaginal ultrasonography and hysteroscopy in the diagnosis of endometrial abnormalities. J Am Assoc Gynecol Laparosc. 1996;3 Suppl 4:S32.

10. Batzer FR. Abnormal uterine bleeding: Imaging techniques for evaluation of the uterine cavity and endometrium before minimally invasive surgery - the case for transvaginal ultrasonography. J Minim Invasive Gynecol. 2007;14(1):9-11.

11. Mitra PK, Roychadhuri J. Effect of oral contraceptives on the ultrastructure of the endometrium. J Gynaecol Endocrinol. 1987;3(1-4): $13-15$.

12. Speroff L, Fritz Marc A. Dysfunctional uterine bleeding. In: Clinical gynecologic endocrinology and infertility. 7th ed. Lippincott Williams \& Wilkins; 2005. p. 548-571.

13. Gal G, Edman CD, Vellios F, Forney JP. Long-term effect of megestrol acetate in the treatment of endometrial hyperplasia. Am J Obstet Gynecol. 1983;146(3):316-322.

14. Munro MG, Mainor N, Basu R, Brisinger M, Barreda L. Oral medroxyprogesterone acetate and combination oral contraceptives for acute uterine bleeding: a randomized controlled trial. Obstet Gynecol. 2006;108(4):924-929.

15. DeVore GR, Owens O, Kase N. Use of intravenous Premarin in the treatment of dysfunctional uterine bleeding: a double-blind randomized control study. Obstet Gynecol. 1982;59:285-291.

16. Paraskevaidis E, Kalantaridou SN, Papadimitriou D. Transvaginal uterine ultrasonography compared with endometrial biopsy for the detection of endometrial disease in perimenopausal women with uterine bleeding. Anticancer Res. 2002;22(3):1829-1832.

17. Getpook C, Wattanakumtornkul S. Endometrial thickness screening in premenopausal women with abnormal uterine bleeding. $J$ Obstet Gynaecol Res. 2006;(6):588-592.

18. Farquhar CM, Lethaby A, Sowter M, Verry J, Baranyai J. An evaluation of risk factors for endometrial hyperplasia in premenopausal women with abnormal menstrual bleeding. Am J Obstet Gynecol. 1999;181(3):525-529.
International Journal of Women's Health

\section{Publish your work in this journal}

The International Journal of Women's Health is an international, peerreviewed open-access journal publishing original research, reports, reviews and commentaries on all aspects of women's healthcare including gynecology, obstetrics, and breast cancer. Subject areas include: Chronic conditions (migraine headaches, arthritis, osteoporosis);

\section{Dovepress}

Endocrine and autoimmune syndromes; Sexual and reproductive health; Psychological and psychosocial conditions. The manuscript management system is completely online and includes a very quick and fair peer-review system. Visit http://www.dovepress.com/ testimonials.php to read real quotes from published authors. 